\title{
Frequency of Serous Otitis Media in Children without Otolaryngological Symptoms
}

\author{
Murat Kocyigit ${ }^{1}$ Safiye Giran Ortekin ${ }^{1}$ Taliye Cakabay ${ }^{1}$ Guven Ozkaya ${ }^{2}$ Selin Ustun Bezgin ${ }^{2}$ \\ Mustafa Kemal Adali ${ }^{3}$
}

${ }^{1}$ Department of Otolaryngology, Kanuni Sultan Süleyman Education and Research Hospital, Istanbul, Turkey

2 Department of Biostatistics, Uludağ University School of Medicine, Bursa, Turkey

${ }^{3}$ Department of Otolaryngology, Bir Nefes Private Hospital,

Luleburgaz, Turkey

Int Arch Otorhinolaryngol 2017;21:161-164.
Address for correspondence Murat Kocyigit, MD, Department of Otolaryngology, Kanuni Sultan Süleyman Education and Research Hospital, Istanbul, Turkey (e-mail: muratdr63@yahoo.com).

\begin{abstract}
Keywords

- tympanometry

- adenoid

- otitis media

Introduction Otitis media with effusion is the fluid in the middle ear with no signs or symptoms of acute ear infection.

Objective This study aims to research the frequency of serous otitis media in patients referred to the pediatric clinic between 3-16 years of age without any active ear, nose, and throat complaints.

Methods This study included 589 children patients (280 boys, 309 girls; mean age: 9.42; range 3-16) who were administered to the pediatric clinic without otolaryngologic complaints. Patients underwent examination with flexible nasopharyngoscopy for adenoid hypertrophy. An otorhinolaryngologist examined all children on both ears using an otoscope and tested with tympanometry. We used tympanometry results to diagnose SOM.

Results The study included 589 patients that underwent fiber optic examination of the nasopharynx with an endoscope. Adenoid vegetation was present in 58 patients (9.8\%) and was not detected in 531 patients (90.2\%). We found serous otitis media in 94 (15.9\%) patients. We obtained Type A tympanogram in $47(81 \%)$ of 58 patients with adenoid vegetation, $6(10.3 \%)$ Type $B$, and $5(8.6 \%)$ Type $C$. When comparing 58 patients with adenoid vegetation with 538 patients without adenoid vegetation for serous otitis media, the frequency was not statistically significant $(p>0.05)$.

Conclusion We believe that in children without any ear, nose, and throat complaints, it is possible to detect serous otitis media with adenoid vegetation. Thus, pediatric patients should undergo screening at regular intervals.
\end{abstract}

\section{Introduction}

Otitis media with effusion (OME) is the fluid in the middle ear with no signs or symptoms of acute ear infection. ${ }^{1}$ Relentless middle-ear fluid from OME results in decreased mobility of the eardrum and serves as a barrier to sound conduction. ${ }^{2}$ The eardrum is often cloudy with distinctly weakened mobility, and an air-fluid level or bubble may be visible in the middle ear. $^{3}$ About 2.2 million diagnosed episodes of OME occur yearly in the United States, resulting in a combined direct and indirect annual cost estimate of four billion dollars. ${ }^{4}$ Approximately $90 \%$ of children have otitis media with effusion before school age, frequently between ages 6 months and 4 years., 6 received

February 11, 2016

accepted

May 4, 2016

published online

June 3, 2016
DOI http://dx.doi.org/

10.1055/s-0036-1584362. ISSN $1809-9777$.
Copyright $\odot 2017$ by Thieme-Revinter

Publicações Ltda, Rio de Janeiro, Brazil
License terms

(요 (1) $\odot \circledast$ 


\section{Objective}

We investigated the frequency of serous otitis media in patients referred to the pediatric clinic between 3-16 years of age without any active ear, nose, and throat complaints in our study.

\section{Methods}

This study included 589 children patients ( 280 boys, 309 girls; mean age: 9.42 ; range 3-16) who were administered to the pediatric clinic without otolaryngologic complaints (-Fig. 1). The Ethics Board granted approval for the study, and each individual signed the informed consent form. The authors declare there was no conflict of interests in this research.

The inclusion criteria applied in the selection of subjects were children belonging to the age group from 3-16 years old. Exclusion criteria were patients aged less than 3 years and over 16 years; patients having active otorhinolaryngological symptoms; cleft palate repair history in the past and cases with submucous cleft palate; and patients having ear wax.

All children underwent an ear, nose, and throat examination. Patients underwent examination with flexible nasopharyngoscope (Fiegert-Endotech, Tuttlingen, Germany) for adenoid hypertrophy. The scaling of adenoid hypertrophy was according to grade given by Clemens and McMurray, ${ }^{7}$ which is: Grade I has adenoid tissue filling 1:3 the vertical tallness of the choana, Grade II up to 2:3, Grade III from 2:3 to almost complete but not completely filling the choana, and Grade IV with complete choanal obstruction. In our study, we considered Grade II-III-IV as adenoid hypertrophy. An otorhinolaryngologist examined all children on both ears using an otoscope and tested them with tympanometry. Tympanometric examinations were done with MAICO m40, (Minneapolis, USA). We classified tympanometric measurement results according to adjusted

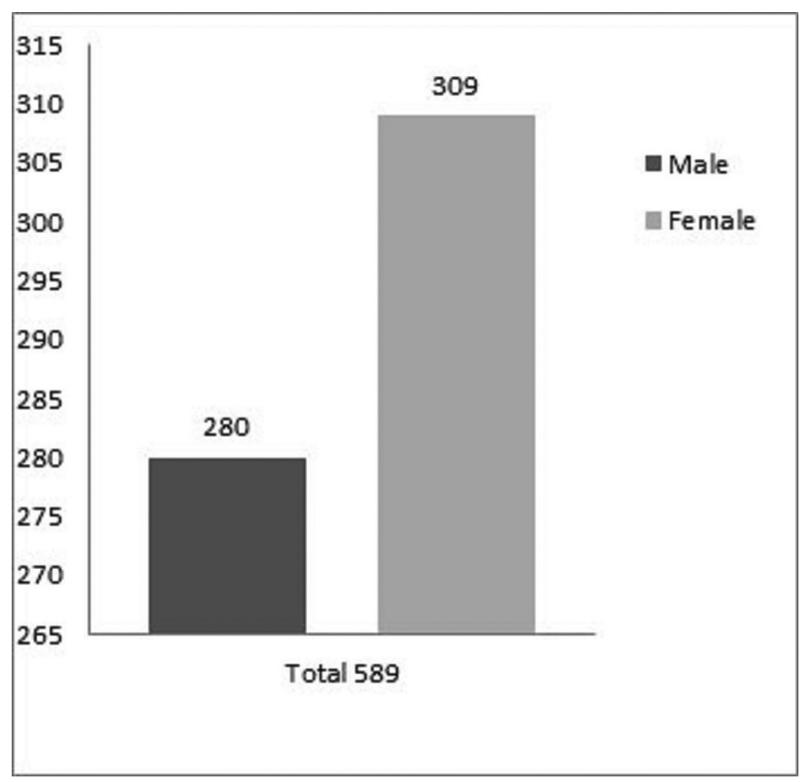

Fig. 1 Variation of patients' genders.
Jerger's classification as types A, As, B, or $C^{8}$ Type A and As curves were accepted as no middle ear effusion while type $B$, type C, and type As as predicting of middle ear effusion. Tympanometry results were used to diagnose EOM.

We performed statistical analyses by using SPSS 22.0 operating program (license no: 10240642). We used the Pearson chi-square test and Fisher-Freeman-Halton test. Each analysis used for each value was defined under the relevant tables. Significance limit was set at $p<0.05$ for all statistics.

\section{Results}

The study included 589 patients that underwent fiber optic examination of the nasopharynx done with an endoscope. Adenoid vegetation was present in 58 patients (9.8\%) and was not detected in 531 patients (90.2\%). Serous otitis media was found in 94 (15.9\%) patients. We detected Grade 2 adenoid vegetation in 22 of 58 patients (38\%), 18 (31\%) had Grade 3, 18 (31\%) had Grade 4 adenoid vegetation (-Fig. 2). We obtained Type A tympanogram for $47(81 \%)$ of the 58 patients with adenoid vegetation, 6 (10.3\%) were Type B, and 5 (8.6\%) Type C. We found serous otitis media frequency in the 58 patients with adenoid vegetation to be $18.9 \%$.

In this study, we obtained Type A tympanogram in 448 patients without adenoid vegetation (84.4\%), Type B in 19 (3.6\%), and Type $C$ in 64 (12\%) patients. We found the incidence rate of serous otitis media in 531 patients without adenoid vegetation to be $15.6 \%$. - Table 1 shows the frequency of adenoid vegetation in patients with and without serous otitis media. When 58 patients with adenoid vegetation compared with 538 patients without adenoid vegetation about serous otitis media, the frequency was not statistically significant ( $\mathrm{p}>0.05)$.

Relation between age range and EOM is not found statistically meaningful $(\mathrm{p}>0.05)$.

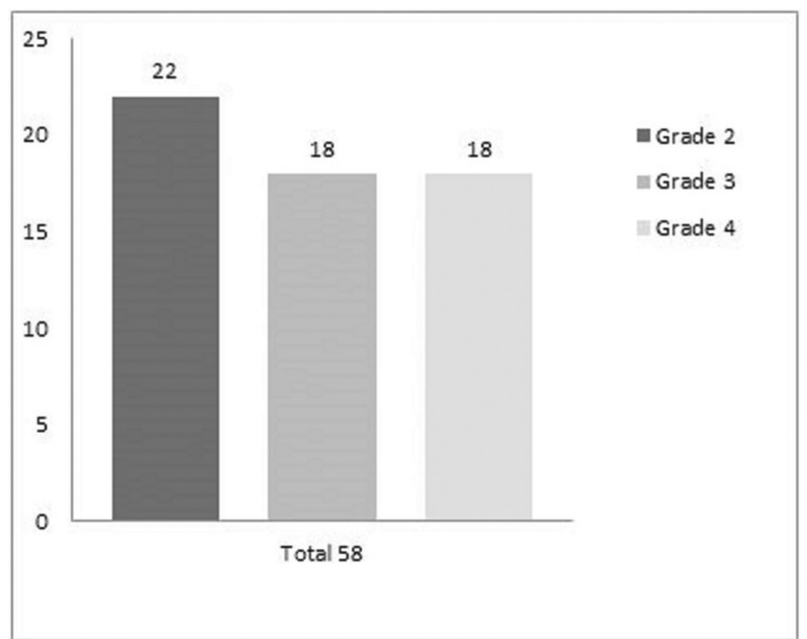

Fig. 2 Grading of patients with adenoid vegetation. 
Table 1 The rates of adenoid vegetation and otitis media with effusion (EOM) in 589 patients

\begin{tabular}{|l|l|l|l|l|}
\hline & Type A tympanogram & Type B tympanogram & Type C tympanogram & EOM frequency \\
\hline $\begin{array}{l}\text { with adenoid } \\
\text { vegetation =58 } \\
(9.8 \%)\end{array}$ & $47(81 \%)$ & $6(10.3 \%)$ & $5(8.6 \%)$ & $11(18.9 \%)$ \\
\hline $\begin{array}{l}\text { without adenoid } \\
\text { vegetation = 531 (90.2\%) }\end{array}$ & $448(84.4 \%)$ & $19(3.6 \%)$ & $64(12 \%)$ & $83(15.6 \%)$ \\
\hline $\begin{array}{l}\text { Total } \\
589\end{array}$ & $495(84.1 \%)$ & $25(4.2 \%)$ & $69(11.7 \%)$ & $94(15.9 \%)$ \\
\hline
\end{tabular}

Abbreviation: EOM, otitis media with effusion.

\section{Discussion}

OME may be spontaneously due to poor eustachian tube function, or as an inflammatory response following acute otitis media. The importance of understanding the OME condition stems from its high prevalence with effusion, difficulties in identifying and assessing duration, increased risk of conductive hearing loss, potential impact on linguistic communication and cognition, and significant practice variations in management. ${ }^{9}$ When the diagnosis of otitis media with effusion is uncertain, tympanometry or acoustic reflectometry should be measured as an adjunct to pneumatic otoscopy. ${ }^{10,11}$ In our study, an otorhinolaryngologist examined all children on both ears using an otoscope and tested them with tympanometry. We used tympanometry results to diagnose otitis media with effusion.

We investigated the frequency of serous otitis media in patients referred to the pediatric clinic between 3-16 years of age without any active ear, nose, and throat complaints in our study.

Williamson et al studied 856 children aged 5 to 8 years from four South West Hampshire schools, which underwent an examination in three-years time by tympanometry, a method used to detect otitis media with effusion (>90\% specificity and sensitivity) performed once per school term. They recorded normal ears in $54.9 \%$ of children with $27 \%$ showing evidence of middle ear effusion. ${ }^{12}$ Our study found similar results, albeit in smaller numbers: 94 of 589 patients (15.9\%) presented serous otitis media. The lower ratio of serous otitis media in our study may be due to the fact that none of the patients included in this study had active otolaryngologic complaints.

Tomonaga et al studied nasopharyngeal bacterial flora in 259 children with otitis media with effusion. The results of this study suggest that adenoid vegetation plays an important role in the etiology of otitis media with effusion. ${ }^{13}$ Sanli et al performed that ear, nose, and throat examination and a questionnaire on 1,165 children from four randomly selected schools. They found that 143 of the patients (12.2\%) had OME. There was significant relation between otitis media with effusion and adenoid vegetation $(p<0.01){ }^{14}$ The incidence of serous otitis media in 58 patients with adenoid vegetation was similar to the rate of $18.9 \%$ in this study. The incidence of serous otitis media is $15.6 \%$ in the 531 patients without adenoid vegetation and the comparison of 58 patients with adenoid vegetation and 538 without adenoid vegetation considering serous otitis media is not statistically meaningful ( $p>0.05)$. This may be because adenoid vegetation does not have much impact on serous otitis media; moreover, the number of the patients with adenoid vegetation $(n=58)$ is less than the number of the patients without adenoid vegetation $(n=531)$, which leads us to consider the reason insufficient.

Otitis media with effusion is highly prevalent in young children. Screening surveys of children in good health ranging in age from infants to age five years show a $15 \%$ to $40 \%$ prevalence of middle-ear effusion., ${ }^{6,21}$ Among children examined at normal intervals for one year, $50 \%$ to $60 \%$ of child care center attendees ${ }^{17}$ and $25 \%$ of school-aged children $^{22}$ had otitis media with effusion at some time during the examination period, with elevated incidence during the winter months. Population-based screening has not impacted short-term language outcomes ${ }^{18}$ and we have not assessed its long-term effects in a randomized clinical trial. Thus, the recommendation for screening is based not only on the ability to identify otitis media with effusion but, more importantly, on a lack of incontrovertible benefits from treating children identified as such that exceed the auspicious natural history of the disease. The New Zealand Health Technology Assessment $^{23}$ could not determine if preschool screening for otitis media with effusion was effective. More recently, the Canadian Task Force on Preventive Health Care ${ }^{24}$ studied that there was insufficient evidence to recommend including or excluding regular early screening for otitis media with effusion. Although screening for otitis media with effusion is not inherently harmful, potential risks include erroneous diagnoses, overtreating self-limited disease, parental fear, and the costs of screening and excessive treatment. Population-based screening is suitable for conditions that are ordinary, can be found by a sensitive and specific test, and provide the advantages stemming from early detection and treatment. ${ }^{25}$ The first two requirements are fulfilled by otitis media with effusion, which affects up to $80 \%$ of children by school entry $4,6,12$ and can be easily screened with tympanometry. Kucur et al reported that the prevalence of OME among 7-12year-old schoolchildren in Erzurum $(n=26)$. Local data provide a population specific standard and can be used in healthcare planning. ${ }^{26}$ Complications of OME especially occur if the disease is not recognized in its early stages and/or treated accordingly. Chronic otitis media, adhesive otitis media, retraction pockets, and tympanosclerosis are the most common complications of chronic OME. When permanent hearing loss develops due to complications, it may lead to impairment in development of speech and language. ${ }^{27}$ 


\section{Conclusion}

As a result, we believe it is possible to detect serous otitis media in children without any ear, nose, and throat complaints with adenoid vegetation. Therefore, pediatric patients should undergo screening at regular intervals. The scan time and frequency terms are needed for further and multicenter studies.

\section{References}

1 Stool SE, Berg AO, Berman S, et al. Otitis media with effusion in young children. Clinical Practice Guideline, Number 12. Rockville, MD: Agency for Health Care Policy and Research, Public Health Service, US Department of Health and Human Services; 1994; AHCPR Publication No. 94-0622

2 Williamson I. Otitis media with effusion. Clin Evid 2002;7(7): 469-476

3 Karma PH, Penttilä MA, Sipilä MM, Kataja MJ. Otoscopic diagnosis of middle ear effusion in acute and non-acute otitis media. I. The value of different otoscopic findings. Int J Pediatr Otorhinolaryngol 1989;17(1):37-49

4 Shekelle P, Takata G, Chan LS, et al. Diagnosis, natural history and late effects of otitis media with effusion. Evidence report/technology assessment no. 55. Rockville, MD: Agency for Healthcare Research and Quality; 2003. AHRQ Publication No. 03-E023

5 Tos M. Epidemiology and natural history of secretory otitis. Am J Otol 1984;5(6):459-462

6 Paradise JL, Rockette HE, Colborn DK, et al. Otitis media in 2253 Pittsburgh-area infants: prevalence and risk factors during the first two years of life. Pediatrics 1997;99(3):318-333

7 Clemens J, McMurray JS, Willging JP. Electrocautery versus curette adenoidectomy: comparison of postoperative results. Int J Pediatr Otorhinolaryngol 1998;43(2):115-122

8 Jerger J. Clinical experience with impedance audiometry. Arch Otolaryngol 1970;92(4):311-324

9 Coyte PC, Croxford R, Asche CV, To T, Feldman W, Friedberg J. Physician and population determinants of rates of middle-ear surgery in Ontario. JAMA 2001;286(17):2128-2135

10 Palmu A, Puhakka H, Rahko T, Takala AK. Diagnostic value of tympanometry in infants in clinical practice. Int J Pediatr Otorhinolaryngol 1999;49(3):207-213

11 Van Balen FA, Aarts AM, De Melker RA. Tympanometry by general practitioners: reliable? Int J Pediatr Otorhinolaryngol 1999;48(2): 117-123

12 Williamson IG, Dunleavey J, Bain J, Robinson D. The natural history of otitis media with effusion-a three-year study of the incidence and prevalence of abnormal tympanograms in four South West
Hampshire infant and first schools. J Laryngol Otol 1994;108(11): 930-934

13 Tomonaga K, Kurono Y, Chaen T, Mogi G. Adenoids and otitis media with effusion: nasopharyngeal flora. Am J Otolaryngol 1989; 10(3):204-207

14 Sanli A, Tasdemir O, Eken M, Celebi O, Yilmaz SH. Prevalence of otitis media with effusion among primary school age-children and etiopathogenic examination. Indian J Otolaryngol Head Neck Surg 2014;66(Suppl 1):95-98

15 Sørensen $\mathrm{CH}$, Holm-Jensen S, Tos M. The post-winter prevalence rate of middle ear effusion in four-year-old children, judged by tympanometry. Int J Pediatr Otorhinolaryngol 1981;3(2):119-128

16 Fiellau-Nikolajsen M. Epidemiology of secretory otitis media. A descriptive cohort study. Ann Otol Rhinol Laryngol 1983;92 (2 Pt 1):172-177

17 Casselbrant ML, Brostoff LM, Cantekin EI, et al. Otitis media with effusion in preschool children. Laryngoscope 1985;95(4):428-436

18 Zielhuis GA, Rach GH, van den Broek P. Screening for otitis media with effusion in preschool children. Lancet 1989;1(8633): 311-314

19 Poulsen G, Tos M. Repetitive tympanometric screenings of twoyear-old children. Scand Audiol 1980;9(1):21-28

20 Tos M, Holm-Jensen S, Sørensen CH. Changes in prevalence of secretory otitis from summer to winter in four-year-old children. Am J Otol 1981;2(4):324-327

21 Thomsen J, Tos M. Spontaneous improvement of secretory otitis. A long-term study. Acta Otolaryngol 1981;92(5-6):493-499

22 Lous J, Fiellau-Nikolajsen M. Epidemiology and middle ear effusion and tubal dysfunction. A one-year prospective study comprising monthly tympanometry in 387 non-selected 7-year-old children. Int J Pediatr Otorhinolaryngol 1981;3(4):303-317

23 New Zealand Health Technology Assessment. Screening programs for the detection of otitis media with effusion and conductive hearing loss in pre-school and new entrant school children: a critical appraisal of the literature. New Zealand, Christchurch: New Zealand. 1998

24 Canadian Task Force on Preventive Health Care. Screening for otitis media with effusion: recommendation statement from the Canadian Task Force on Preventive Health Care. CMAJ 2001; 165(8):1092-1093

25 US Preventive Services Task Force. Guide to clinical preventive services, 2nd ed. Baltimore, MD: Williams \& Wilkins; 1995

26 Kucur C, Şimşek E, Kuduban O, Özbay İ. Prevalence of and risk factors for otitis media with effusion in primary school children: case control study in Erzurum, Turkey. Turk J Pediatr 2015;57(3): 230-235

27 Varsak YK, Gül Z, Eryılmaz MA, Arbağ H. Prevalence of otitis media with effusion among school age children in rural parts of Konya province, Turkey. Kulak Burun Bogaz Ihtis Derg 2015;25(4): 200-204 